\title{
GESTÃO HÍDRICA A PARTIR DE CISTERNAS DE PLACAS: AVALIAÇÃO SOCIOAMBIENTAL DA EFICIÊNCIA DO PIMC NO MUNICÍPIO DE PEDRA LAVRADA-PB
}

\author{
J. A. L. SILVA', M. C. S. MEDEIROS'1, J. P. DE FREITAS', H. F. S. A. DANTAS' ${ }^{1}$ e P. V. AZEVEDO ${ }^{2}$ \\ 12 Unidade Acadêmica de Ciências Atmosférica - UACA, Universidade Federal de Campina Grande - UFCG. \\ adailton_limasilva@hotmail.com; monalisacistina@hotmail.com; janierk_pfreitas@hotmail.com; \\ helinefernanda@hotmail.com; pvieira@dca.ufcg.br.
}

Artigo submetido em novembro/2013 e aceito em dezembro/2013

DOI: 10.15628/holos.2014.1541

\section{RESUMO}

Atualmente, muitas populações rurais do Semiárido brasileiro têm convivido com árduas realidades em virtude da carência de água. Diante disto, as cisternas de placas surgem como mecanismo para prover o acesso e disponibilidade de água. Neste sentido, a Articulação do Semiárido (ASA) elaborou o "Programa Um Milhão de Cisternas Rurais - P1MC", o qual busca prover o gerenciamento e a valorização da água para a "convivência sustentável" com a escassez de água no Semiárido brasileiro. Conhecendo-se as premissas do $\mathrm{P} 1 \mathrm{MC}$, o presente estudo objetivou analisar a eficiência das cisternas de placas e o desempenho do P1MC para com a disponibilidade de água, e a melhoria da qualidade de vida das famílias que convivem com a escassez hídrica. Para tanto, foram realizados: i) estudos sobre a pluviometria (série de 61 anos de precipitação pluvial); ii) estimativa do Volume Potencial de Captação (VPC) dos telhados residenciais e das cisternas; e iii) aplicação de questionários semiestruturados a 40 famílias beneficiadas pelo P1MC, no município de Pedra Lavrada - PB. Como resultados, concluiu-se que: 1 ) as cisternas de placa é uma tecnologia eficiente e capaz de suprir as necessidades hídricas durante o período de estiagem (8 meses); 2) o P1MC apresentou pontos negativos: ausência de fiscalização das cisternas com problemas (rachaduras e vazamentos), e a impossibilidade de atender aos anseios familiares (dessedentação animal ou cultivo de pequenas lavouras); e 3) o P1MC promoveu o acesso/disponibilidade de água, e "independência hídrica", promovendo assim a sustentabilidade das famílias rurais em meio às adversidades edafoclimáticas do Semiárido brasileiro.

PALAVRAS-CHAVE: Escassez d'água, gestão hídrica, melhorias socioambientais

\section{MANAGING WATER TANKS FROM THE BOARDS: SOCIO-ENVIRONMENTAL ASSESSMENT OF EFFICIENCY IN P1MC THE CITY OF PEDRA LAVRADA-PB}

\section{ABSTRACT}

Currently, many rural populations of the Brazilian semiarid region have lived with tough realities due to the lack of water. Given this, the cisterns arise as a mechanism for providing access and availability of water. In this sense, the Semi-Arid Articulation (ASA) has developed the "One Million Rural Cisterns - P1MC", which seeks to provide the management and valuation of water for "sustainable living" with the shortage of water in the Brazilian semiarid region. Knowing the assumptions $\mathrm{P} 1 \mathrm{MC}$, the present study aimed to analyze the efficiency of cisterns and performance P1MC to the availability of water, and improving the quality of life for families living with water scarcity. So, were performed: i) studies on rainfall (number of 61 year rainfall), ii) estimate the
\end{abstract}

Volume Potential Funding (VPC) of residential roofs and tanks, and iii) application of semi-structured questionnaires to 40 families benefited by P1MC, in Pedra Lavrada - PB. As results, it was concluded that: 1) tanks card is efficient technology and capable of meeting the water needs during the dry period ( 8 months), 2) the P1MC presented negatives: lack of inspection of tanks with problems (cracks and leaks), and the inability to meet the yearnings family (watering animals or growing small crops), and 3) the P1MC promoted access / availability of water and "water independence", promoting the sustainability of rural households in midst of adversity edaphoclimatic the Brazilian semiarid region.

KEYWORDS: Water scarcity, water management, socio-environmental improvements 


\section{INTRODUÇÃO}

Desde tempos remotos, muitas são as sociedades que convivem com realidades adversas em virtude da escassez hídrica. Neste universo, "o crescimento populacional e a degradação dos recursos hídricos, aliado ao uso irracional da água, ao manejo inadequado, dentre outros, têm contribuído de forma decisiva para reduzir a oferta de água nos mananciais hídricos" (OLIVEIRA et al., 2012).

No Brasil, a falta de água tem fomentado cenários socioeconômicos preocupantes, em especial na região semiárida brasileira, que abrange oito estados do Nordeste e o Norte de Minas Gerais, onde a situação de escassez hídrica tem atingido aproximadamente 20 milhões de pessoas (BRASIL, 2005).

Na região semiárida brasileira, os recursos hídricos são escassos, com mananciais não perenes que podem permanecer secos durante grande parte do ano. Dessa forma, os problemas correlacionados com a indisponibilidade de água são muitos: grande esforço físico por parte das famílias que caminham longos percursos a procura de água; comprometimento do desenvolvimento socioeconômico local; e aumento do número de casos de doenças provenientes da ingestão de água de baixa qualidade. Como reforço a esta última afirmativa, tem-se que "de cada quatro mortes de crianças na região do Semiárido, estima-se que uma é devido à diarreia causada por água contaminada" (FOME ZERO, 2005).

Somado aos problemas socioeconômicos, muitas são as "consequências ambientais" relacionadas à escassez hídrica, a saber: a) a perda da umidade do solo o torna pobre em matéria orgânica e, consequentemente, mais pobre e estéril; b) com o solo mais seco e menos denso, o processo de erosão eólica torna-se mais efetivo; e c) com a escassez de água no solo, a vegetação perde sua pujança e reduz a oferta de sementes e frutos.

Diante do contexto descrito, os problemas socioeconômicos e as "consequências ambientais" atribuídos à indisponibilidade de água têm fomentado uma louvável temática: "como a gestão de recursos hídricos pode prover melhorias de vida para as sociedades que convivem com escassez hídrica?". Tal questionamento tem sido respondido através de inúmeras tentativas de implantar estratégias de convivência com o Semiárido, baseadas principalmente em tecnologias que reduzam o desperdício de água, envolvendo coleta, armazenamento e manejo de água de chuva, construção e manutenção de pequenos barramentos, implantação de barragens subterrâneas, entre outras (BRASIL, 2005).

Sabendo-se que num mundo de causa/efeito se tem a escassez de água como causa de condições de vida adversas, e que ela propicia, ainda, muitas famílias a viverem a "duras penas", é indispensável que se possa conduzir um trabalho de gestão dos recursos hídricos, onde se projete o aproveitamento da água de forma sustentável. Neste sentido, uma das iniciativas mais racionais para prover o acesso à água, veio através da Articulação do Semiárido Brasileiro (ASA), que criou em 2000, o "Programa de Formação e Mobilização Social para a Convivência com o Semiárido: Um Milhão de Cisternas Rurais - P1MC". Esse programa tem como objetivo principal a construção de um milhão de cisternas rurais, procurando beneficiar aproximadamente cinco milhões de pessoas 
que convive com o problema da escassez de água na região semiárida do Nordeste brasileiro (SILVA, 2007).

A importância do P1MC enquanto provedor de uma tecnologia de gestão hídrica (cisternas de placas) remonta-se a possibilidade de prover melhor qualidade de vida para famílias que convivem com a escassez de água, fazendo com que haja o acesso, o gerenciamento e a valorização da água, ampliando a compreensão e a prática da convivência sustentável e solidária com problemas relacionados à carência de água (BARBOSA, 2005).

Conhecendo-se as premissas e princípios do P1MC, torna-se imprescindível a realização de estudos que possam comprovar a eficiência da implantação do sistema de gestão a partir da captação e aproveitamento de água de chuva em cisternas de placas, assim como também obter um grau de confiabilidade do P1MC a partir de uma pesquisa junto às famílias beneficiadas pelo supracitado programa. Dessa forma, o presente estudo avança no sentido de avaliar a eficiência do P1MC diante de cenários (realidades) pluviais divergentes: regime pluvial maior ou menor do que o esperado, ou seja, analisar a viabilidade das cisternas de placas frente à variabilidade pluvial.

Face ao exposto até o momento, o presente estudo objetivou analisar a eficiência e desempenho do Programa Um Milhão de Cisternas Rurais (P1MC) no sentido de sua contribuição para a gestão hídrica e melhoria da qualidade de vida das sociedades rurais, assim como também, para promoção da convivência sustentável com as condições ambientais do Semiárido brasileiro.

\section{MATERIAL E MÉTODOS}

\subsection{Espaço de pesquisa}

O presente trabalho realizou-se junto às famílias rurais no município de Pedra Lavrada (latitude $06^{\circ} 45^{\prime} 25^{\prime \prime} \mathrm{S}$; longitude $36^{\circ} 28^{\prime} 49^{\prime \prime} \mathrm{W}$ e altitude: 516 metros), situado na microrregião do Seridó Oriental do estado da Paraíba (Figura 1). O referido município está situado a cerca de 230 $\mathrm{km}$ de distância da capital paraibana, João Pessoa, abrangendo uma área de $351 \mathrm{~km}^{2}$ e uma população de 7.475 (IBGE, 2010). 


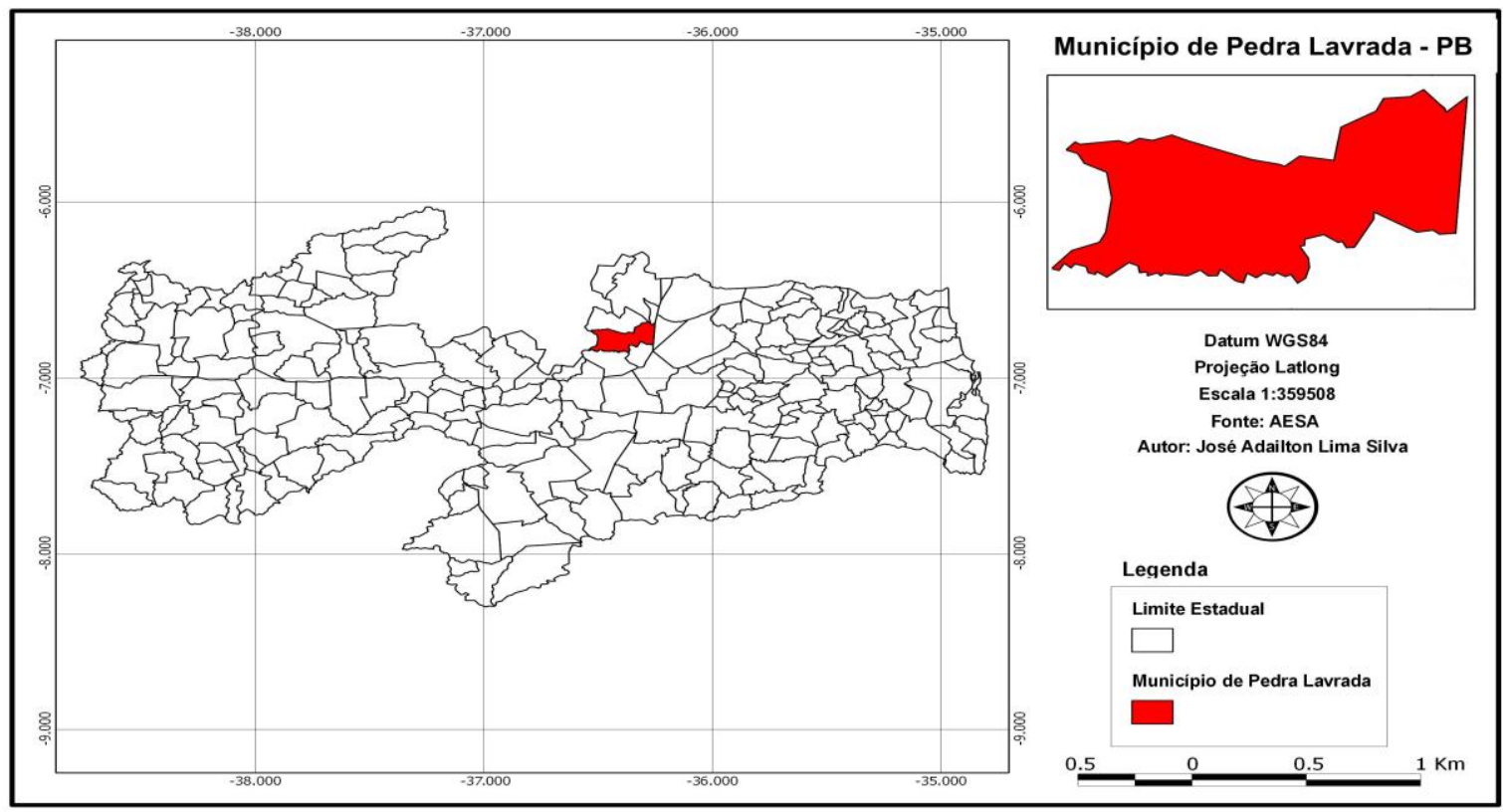

Figura 1 - Localização do município de Pedra Lavrada - PB Fonte - AESA, (2013).

No tocante aos aspectos geomorfológicos, o município localiza-se sobre o Maciço précambriano do Planalto da Borborema, com morfologia suavemente ondulada, e com predominância de solos rasos e cristalinos: gnaisses, micaxistos e granitos, predominando os tipos Bruno-não- Cálcico, Litólico e Aluvião (SAMPAIO et al. 2003, p.118). A vegetação local é a caatinga Seridó, vegetação peculiar a esta região e que se caracteriza por ser uma vegetação hiperxerófila aberta constituída por plantas atrofiadas de porte arbustivo e/ou arbóreo e esparsas (ANDRADE, 1981).

Com relação ao clima, o município de Pedra Lavrada - PB detém como clima o subdesértico quente de tendência tropical, com 9 a 11 meses secos. A pluviosidade média anual é de $406 \mathrm{~mm}$, de distribuição irregular com $79 \%$ de seu total concentrando-se em 04 meses, e a temperatura média anual é de $27 \stackrel{\circ}{\circ}$ a $28{ }^{\circ} C^{\circ}$ (MMA, 2005).

A necessidade de tomar o município de Pedra Lavrada - PB como foco para o referido plano de estudo justifica-se em virtude de dados socioeconômicos relevantes, a saber: a) dentre os 7.475 habitantes, mais de $58 \%$ da população local (4.400 pessoas) residem na zona rural e são as mais vulneráveis a problemática que envolve a indisponibilidade hídrica; b) dos domicílios existentes no município, perfazendo um total de 2.239, cerca de 1.257 residências (57\%) não possuem abastecimento de água; e c) dentre 3.410 trabalhadores com renda no município, menos de $49 \%$ desta população (1.670 pessoas) estão no campo e desempenhando atividades como agricultura, pecuária, as quais necessitam da disponibilidade de recursos hídricos (IBGE, 2010).

Sucintamente, a escolha do município de Pedra Lavrada - PB está no fato de sua população rural estar submetida à escassez hídrica proveniente das condições climáticas, e por não prover de mecanismos de gestão hídrica e depender, essencialmente, das cisternas de placas como meio de captação e armazenamento da água para o consumo humano e doméstico. 


\subsection{Procedimento metodológico}

Esta é uma pesquisa exploratória delineada com o método de observação e análise de natureza qualitativa, quantitativa, descritiva e interdisciplinar.

A metodologia utilizada neste trabalho valeu-se, inicialmente, de uma série ininterrupta de dados de precipitação pluvial - mensais e anuais - do município de Pedra Lavrada - PB, cedida pela Agência Executiva de Gestão das Águas do Estado da Paraíba (AESA) e pelo Instituto Nacional de Meteorologia (INMET), correspondente ao período de 1962 a 2012, para inferência estatística. Lançando mãos dos dados, agruparam-se tais dados, ordenando-os, cronologicamente, de forma mensal (soma dos valores diários) e anual (somatório dos totais mensais). Posteriormente, determinou-se as medidas de tendência central (média aritmética e mediana) e de dispersão (desvio padrão), isso em consonância com os critérios e fórmulas propostas por Assis et al. (1996).

Ao conhecer a grande variabilidade do regime pluvial no tempo e no espaço, consequentemente, as incertezas na quantidade anual de precipitação, irão incluir-se quatro cenários pluviais distintos, a saber: média do período, o ano mais seco, ano mais chuvoso, e o valor da mediana da série ( $50 \%$ de probabilidade). Isso para determinar a adaptabilidade do P1MC aos possíveis cenários (realidades) hídricos do Semiárido brasileiro. Neste sentido, calculou-se a precipitação média do município, considerando-se os valores das precipitações obtidos durante uma série de 60 anos de registro anual, colocando em ordem decrescente, determinando-se a probabilidade de ocorrência pela fórmula:

$$
P=\frac{N}{n+1} \times 100
$$

Sendo: $\mathrm{P}=$ a probabilidade de ocorrência $\% ; \mathrm{N}=$ o número de ordem; $\mathrm{n}$ = o número total de anos observados.

Em seguida, foram dimensionadas as áreas de captação dos telhados das residências rurais, a fim de conhecer os Volumes Potenciais de Captação (VPC) de água da chuva. Para tanto, foram calculados, para cada um dos quatro cenários pré-estabelecidos, o regime pluvial, multiplicando-o pela área de cobertura das residências e o Coeficiente de Escoamento (Ce), mediante a expressão: $V c$ (litros) = totais de chuva (em, $\mathrm{mm}) \times$ área do telhado $\left(\mathrm{em}, \mathrm{m}^{2}\right) \times C e$. O coeficiente de escoamento utilizado foi de 0,75 , valor este recomendado por Silva et al. (1993) para áreas de captação cobertas com telhas de barro.

Uma vez conhecido o volume potencial de captação (VPC), determinou-se uma relação entre os potenciais possíveis de captação versus consumo de água, isso para avaliar a eficiência do P1MC enquanto modelo de gestão hídrica, e como instrumento para fomentar a qualidade de vida através do acesso e disponibilidade de água. Assim, foi calculado o volume total de água para suprir as necessidades das pessoas durante um determinado período, utilizou-se a fórmula:

$\mathrm{Vt}=1,1(\mathrm{~N} \times \mathrm{S} \times \mathrm{U}) / 1000$ equação (2)

Onde o número de pessoas está representado por $\mathrm{N}$, o consumo diário de água por $\mathrm{S}$, e o período de água da cisterna por U. Todas as variáveis são multiplicadas por 1,1 correspondentes às perdas de água por desperdício, estimadas em 10\% (SILVA et al., 1993).

Num outro momento, foi realizada uma pesquisa participante, pois através dela estabeleceu-se relações comunicativas com pessoas ou grupos da situação investigada, isso com o 
intuito de serem mais bem aceitos enquanto desempenham um papel ativo no equacionamento dos problemas encontrados, no acompanhamento e na avaliação das ações desencadeadas (THIOLLENT, 2005).

Ainda como ressalva ao método da pesquisa participante, de acordo com Alves et al. (2008), na pesquisa participativa o problema origina-se na comunidade em estudo e a última finalidade da pesquisa é a transformação estrutural fundamental e melhoria da vida dos envolvidos. Neste sentido, a pesquisa buscará analisar a percepção social sobre o Programa Um Milhão de Cisternas Rurais (P1MC) enquanto um modelo de gestão de recursos hídricos, e quais os possíveis benefícios e problemas atribuídos a este "programa social". Para tanto, foram realizadas, conforme Pedrosa (2011), entrevistas e aplicação de questionários semiestruturados com um grupo de 40 famílias rurais que foram beneficiadas com o P1MC no município de Pedra Lavrada - PB, perfazendo uma amostra de $8,4 \%$ das 476 famílias contempladas pelo P1MC.

As entrevistas e os questionários semiestruturados abstraíram variáveis indispensáveis a pesquisa, como: a) percepção social sobre os benefícios advindos do programa P1MC; b) os efeitos do P1MC para as condições de vida e saúde das famílias; e, por fim, e) quais os possíveis problemas atribuídos ao P1MC e os anseios das famílias beneficiadas pelo supracitado programa.

Por fim, ressalva-se que todos os cálculos e análises estatísticas dos dados foram realizados através do software Microsoft Excel $^{\oplus}$ 2007. Para o cálculo matemático dos dados qualiquantitativos coletados em campo, utilizou-se a estatística descritiva, pois esta "preocupa-se com a forma pela qual podemos apresentar um conjunto de dados em tabelas e gráficos, e também resumir as informações contidas nestes dados mediante a utilização de medidas estatísticas" (BARBETTA, 2002).

De forma sucinta e concisa, o presente estudo conduziu, a partir de uma análise qualiquantitativa de dados e da percepção das famílias sobre o P1MC, uma avaliação socioambiental acerca da eficiência das cisternas de placas e o desempenho do P1MC enquanto modelo de gestão hídrica.

\section{RESULTADOS E DISCUSSÕES}

3.1 Eficiência do P1MC: Análise do regime pluvial e dos Volumes Potenciais de Captação (VPC) das cisternas de placas para suprir as necessidades familiares

O P1MC, como visto, utiliza as cisternas de placas como uma tecnologia social para aumentar a disponibilidade de água. Por isso, inicialmente foram determinados as características do regime pluvial do município de Pedra Lavrada - PB, a fim de estimar os Volumes Potenciais de Captação (VPC). Neste sentido, analisou-se, inicialmente, uma série de 61 anos (duas médias climatológicas: 1952-2012) de precipitação pluvial e determinou-se a probabilidade de chuva para o município de Pedra Lavrada (Quadro 1). 
Quadro 1: Totais anuais de precipitação $(\mathrm{mm})$ e a Probabilidade de ocorrência para quatro cenários: ano mais seco, ano mais chuvoso, média e mediana (50\%) da série (1952 a 2012) para o município de Pedra Lavrada-PB.

\begin{tabular}{|c|c|c|c|}
\hline № ordem & Anos & Precipitação Acumulada (mm) & Probabilidade de Ocorrência (\%) \\
\hline 1 & 1974 & 921,4 (ano mais chuvoso) & 1,6 \\
\hline 2 & 1986 & 880,2 & 3,2 \\
\hline 3 & 1985 & 852,3 & 4,8 \\
\hline 4 & 2011 & 809,7 & 6,4 \\
\hline 5 & 1964 & 774,3 & 8,1 \\
\hline 6 & 2010 & 769,6 & 9,7 \\
\hline 7 & 2000 & 759,5 & 11,3 \\
\hline 8 & 1971 & 725,3 & 12,9 \\
\hline 9 & 2009 & 713,9 & 14,5 \\
\hline 10 & 1977 & 673,8 & 16,1 \\
\hline 11 & 2008 & 662 & 17,7 \\
\hline 12 & 1963 & 655 & 19,3 \\
\hline 13 & 1975 & 641,4 & 21 \\
\hline 14 & 2004 & 616,3 & 22,6 \\
\hline 15 & 1994 & 588,8 & 24,2 \\
\hline 16 & 1966 & 520,8 & 25,8 \\
\hline 17 & 2002 & 501,6 & 27,4 \\
\hline 18 & 1967 & 500,2 & 29,0 \\
\hline 19 & 1997 & 495,4 & 30,6 \\
\hline 20 & 1969 & 473 & 32,2 \\
\hline 21 & 1981 & 451,2 & 33,9 \\
\hline 22 & 1960 & 440,1 & 35,5 \\
\hline 23 & 1984 & 430,2 & 37,1 \\
\hline 24 & 1968 & 417,5 & 38,7 \\
\hline 25 & 1978 & 417,5 & 40,3 \\
\hline 26 & 1976 & 417,2 & 41,9 \\
\hline 27 & 1972 & 412,5 & 43,5 \\
\hline 28 & 1988 & 407,6 (média da série) & 45,2 \\
\hline 29 & 2006 & 401,8 & 46,8 \\
\hline 30 & 1973 & 380,4 & 48,4 \\
\hline 31 & 1961 & 366,3 (mediana) & 50 \\
\hline 32 & 1996 & 342,1 & 51,6 \\
\hline 33 & 2003 & 334,7 & 53,2 \\
\hline 34 & 1965 & 333,4 & 54,8 \\
\hline 35 & 1995 & 332,7 & 56,5 \\
\hline 36 & 1991 & 327,6 & 58,1 \\
\hline 37 & 1999 & 324,5 & 59,7 \\
\hline 38 & 1987 & 323,2 & 61,3 \\
\hline 39 & 2005 & 320,3 & 62,9 \\
\hline 40 & 2007 & 299,2 & 64,5 \\
\hline 41 & 1982 & 297,4 & 66,1 \\
\hline 42 & 1979 & 286,9 & 67,7 \\
\hline 43 & 1989 & 282,7 & 69,3 \\
\hline 44 & 1956 & 270,9 & 70,97 \\
\hline 45 & 1954 & 237 & 72,6 \\
\hline 46 & 1980 & 221,6 & 74,2 \\
\hline 47 & 1955 & 214 & 75,8 \\
\hline 48 & 2001 & 201 & 77,4 \\
\hline 49 & 1992 & 199,4 & 79,0 \\
\hline 50 & 1970 & 193,6 & 80,6 \\
\hline
\end{tabular}




\begin{tabular}{|c|c|c|c|}
\hline 51 & 1959 & 183,3 & 82,3 \\
\hline 52 & 1957 & 181,9 & 83,9 \\
\hline 53 & 1983 & 166,8 & 85,5 \\
\hline 54 & 1962 & 157,4 & 87,1 \\
\hline 55 & 1998 & 140,4 & 88,7 \\
\hline 56 & 1958 & 118,1 & 90,3 \\
\hline 57 & 1990 & 100,4 & 91,9 \\
\hline 58 & 1952 & 99,2 & 93,5 \\
\hline 59 & 1953 & 96 & 95,2 \\
\hline 60 & 2012 & 70 & 96,8 \\
\hline 61 & 1993 & 60,7 (ano mais seco) & 98,4 \\
\hline
\end{tabular}

Fonte - Elaborada com base em dados obtidos no INMET e na AESA

Ao analisar o Quadro 1, pode-se observar que a precipitação anual média da série para o município de Pedra lavrada foi de 407,6 mm, correspondendo a uma probabilidade de 45,2\%, número menor que $50 \%$, correspondendo à mediana da série. Neste sentido, tornou-se plausível utilizar a mediana (366,3 mm) para estimar os Volumes Potenciais de Captação (VPC), isso porque aumentado-se a probabilidade $(45,2$ da média para $50 \%$ da mediana), aumenta-se consequentemente a certeza de ocorrer o evento esperado (precipitação). Assim, a mediana (50\%) tornou-se a premissa pluviométrica porque ela possibilita concluir, estatisticamente, que: a cada dois anos, um terá precipitação igual ou maior que $366,3 \mathrm{~mm}$.

De posse dos dados pluviais e da probabilidade de ocorrência das quantidades esperadas, pôde-se estimar o volume de chuva para um próximo ciclo, tornando-se possível estimar o escoamento médio esperado para o armazenamento de água nas cisternas. Com isso, averiguouse a eficiência das cisternas de placas enquanto um sistema de gestão hídrica "confrontando-a" com possíveis cenários climáticos pertinentes aos anos secos e chuvosos. Neste sentido, foram pré-estabelecidos quatro cenários pluviais distintos, a saber: média da série $(406,4 \mathrm{~mm})$, o ano mais seco (1993 - 60,7 mm), o ano mais chuvoso (1974 - 921,4 mm), e o da mediana da série (366,3 $\mathrm{mm}$ ) que corresponde ao nível de $50 \%$ de probabilidade (Figura 3 ).

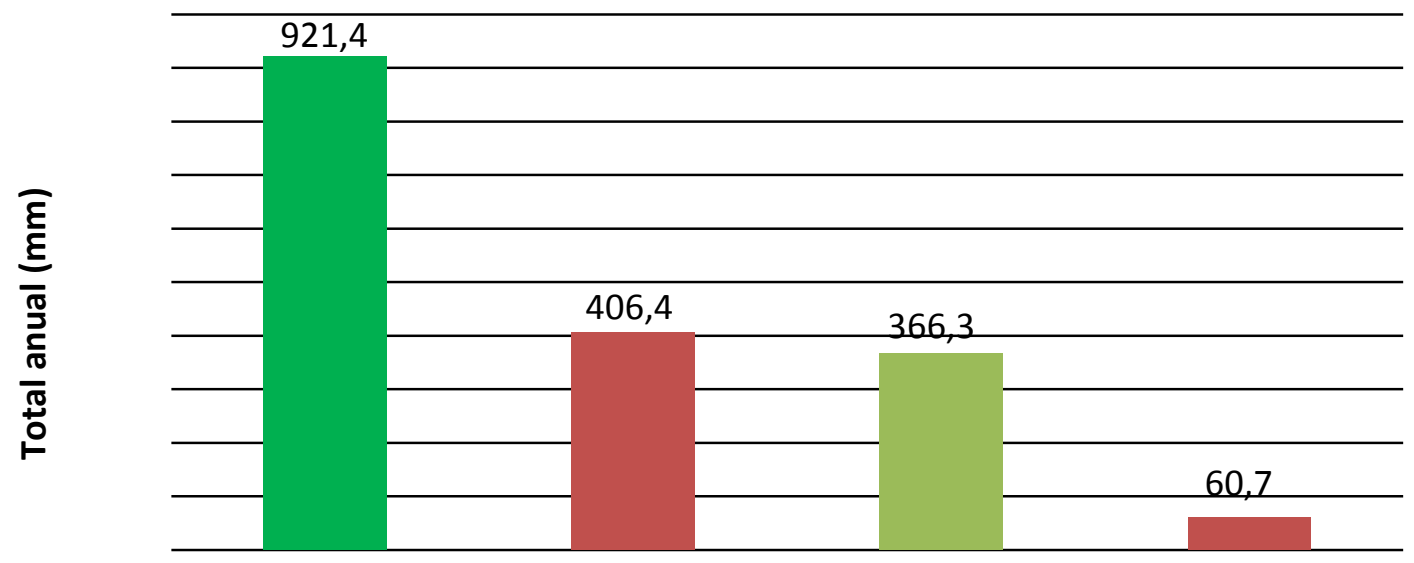

\section{Cenários}

Figura 3 - Totais anuais de precipitação pluvial para os cenários pré-estabelecidos

Ao lançar mãos dos dados da precipitação para três cenários específicos (ano mais seco, mediana - 50\%, e ano mais chuvoso) e comparando-os com as áreas de captação dos telhados das 
residências rurais $\left(40,50,63\right.$ e $\left.100 \mathrm{~m}^{2}\right)$, pôde-se conhecer os Volumes Potenciais de Captação (VPC) de água da chuva para cada um dos três cenários de regime pluvial (Figura 4).

⿴囗大 60,7 mm $\square$ Mediana $(366 \mathrm{~mm}) \quad \square 921,4 \mathrm{~mm}$

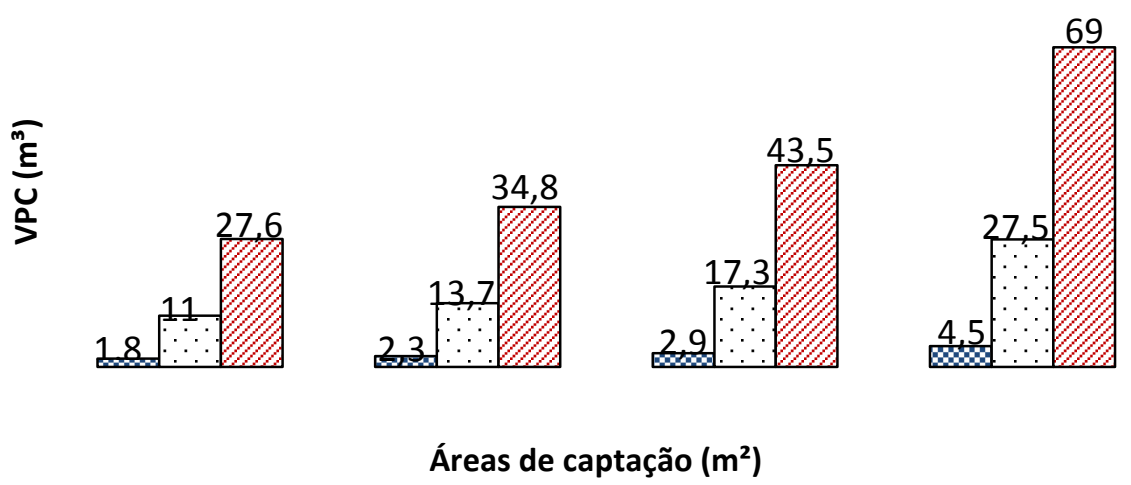

Figura 4 - Volumes Potenciais de Captação de água de chuva (VPC) para quatro áreas de captação, estimado a partir de três cenários pluviais: $60,7 \mathrm{~mm}, 366 \mathrm{~mm}, 921,4 \mathrm{~mm}$

Observa-se na Figura 4 que, tomando a precipitação de $366,6 \mathrm{~mm}$ (mediana da série) para uma área de $63 \mathrm{~m}^{2}$ (tamanho médio dos telhados das residências pesquisadas), tem-se um VPC de 17,3 mil litros, o que é capaz de encher a cisterna de placa (16 mil litros) e atender aos ditames do P1MC.

Uma vez conhecido o volume potencial de captação (VPC), determinou-se uma relação entre os potenciais possíveis de captação versus consumo, isso para avaliar a eficiência do P1MC enquanto tecnologia de gestão hídrica capaz de fomentar a qualidade de vida através do acesso e disponibilidade de água. Assim, foi calculado o volume total de água para suprir as necessidades humanas (para consumo e higiene pessoal), que exige uma demanda de aproximadamente 14 litros de água por pessoa, por dia (Silva, 2006). Nesta perspectiva, tornou-se plausível apresentar a correlação dos dados da precipitação correspondente a 366,3 mm (mediana da série) com o valor de consumo de água por família (Figura 5).

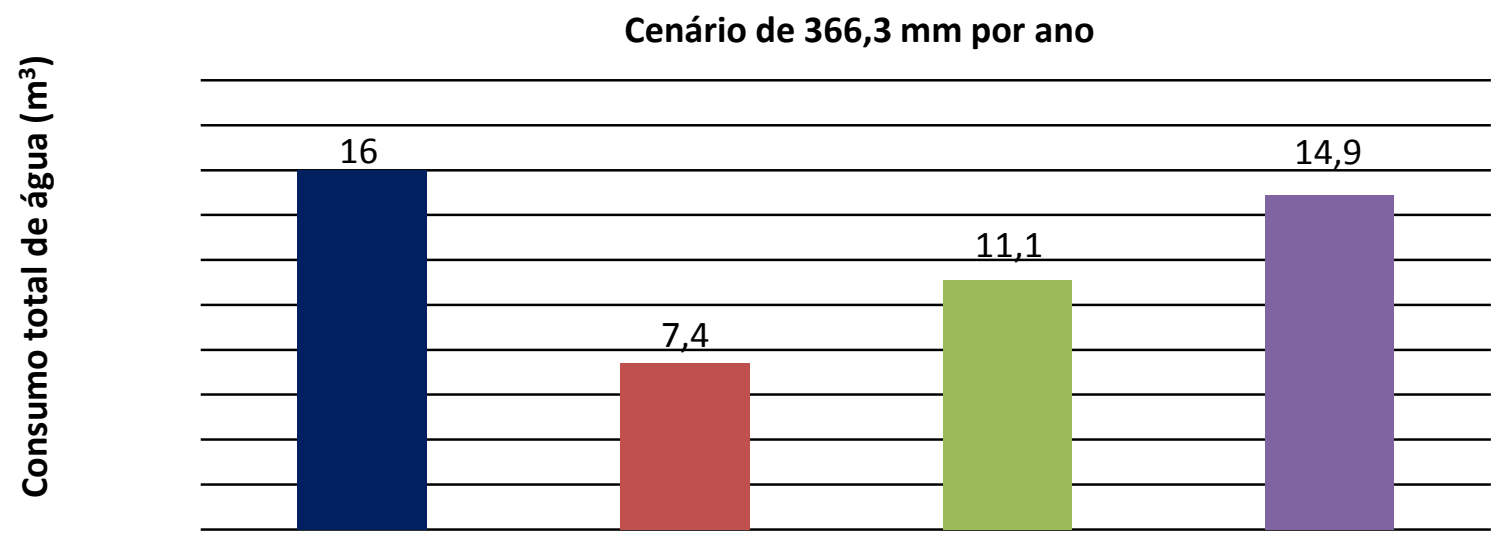

Quantidade de pessoas por família

Figura 5 - Correlação entre o consumo total de água e o número de pessoas por família, considerando a precipitação de $366,3 \mathrm{~mm}$ (mediana da série) 
Diante dos dados da Figura 5, observa-se que: tomando-se a expectativa de 366,3 $\mathrm{mm}$ de chuva por ano (mediana da série), a dimensão das cisternas de placas do P1MC (16 mil litros) pode atender à demanda hídrica de um grupo de quatro pessoas por família, equivalendo à média de pessoas por famílias pesquisadas no município de Pedra Lavrada - PB. Assim, nota-se que as cisternas de placas construídas pelo $\mathrm{P} 1 \mathrm{MC}$ são uma tecnologia viável para solucionar a falta de água, pelo menos, para suprir à quantidade necessária e vital ao consumo humano (ALMEIDA \& SILVA, 2001).

\subsection{Avaliação sobre o consumo e problemas do desempenho do P1MC}

Quanto à utilização da água armazenada nas cisternas de placas, contraditoriamente ao objetivo do P1MC que é prover água em quantidade adequada para suprir apenas a sede das famílias, a mesma é utilizada em outras atividades: a) higiene pessoal (95\%); b) lavagem de roupa e domicilio (90\%), e dessedentação de animais (45\%). Ver Figura 6.

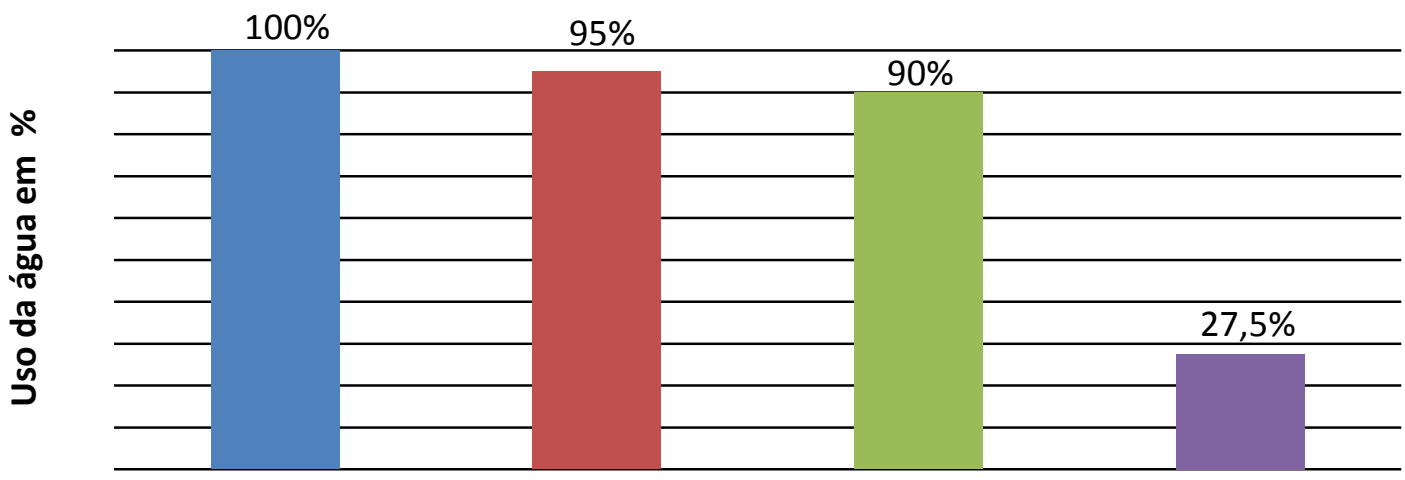

Modos de uso da água

Figura 6 - Múltiplos usos da água acumulada nas cisternas

Como visto, a água das cisternas tem múltiplos usos, fato que faz com que a água acumulada na cisterna dure em média 3,8 meses (114 dias), e uma vez não sendo atendidas suas necessidades hídricas durante o restante dos meses de estiagem, 100\% das famílias pesquisadas acabam por comprar água através de carros-pipa. Tal realidade denuncia um dos pontos negativos do P1MC: a quantidade de água nas cisternas não atende a todos os anseios das famílias.

Outro problema correlacionado à efetivação do P1MC no município de Pedra Lavrada-PB, diz respeito ao fato de $27,5 \%$ das famílias estão desprovidos de qualquer acompanhamento por parte do P1MC para fiscalizar as rachaduras, infiltrações e vazamentos nas cisternas que podem conduzir a contaminação da água por agentes patógenos externos.

\subsection{P1MC: Sustentabilidade para o Semiárido brasileiro}

A construção de cisternas de placa pelo P1MC, tem se configurado numa tecnologia social de ampla contribuição para a sustentabilidade no Semiárido brasileiro. Segundo Silva (2006), as tecnologias sociais são definidas como:

Inovações simples, de baixo custo, de fácil implantação e de grande impacto social, aplicáveis as mais diversas áreas do conhecimento. Constituem um 
importante componente das estratégias de desenvolvimento local sustentável, pois podem incidir, favoravelmente, na melhoria das condições de vida das comunidades onde são implementadas (SILVA, 2006).

Diante da ressalva acima, sabe-se que as cisternas de placas do P1MC têm cumprido com seu papel enquanto uma tecnologia social, pois elas além de representarem uma tecnologia de fácil construção e baixo custo, também têm melhorado as condições de vida das comunidades rurais através do acesso e disponibilidade de água.

Uma tecnologia social é forjada a partir dos anseios sociais e construída a partir das necessidades daqueles a quem se destina a tecnologia, divergentemente das que atendem os ditames dos modelos tecnológicos desenvolvimentistas pautados em "interesses particulares". Neste sentido, encontra-se aqui mais uma característica do P1MC que contribui para a sustentabilidade no Semiárido: possibilitar a "independência hídrica", ou seja, fazer as famílias serem independentes de ações populistas (manobras políticas), as quais visam interesses particulares, e não as necessidades da coletividade (população).

Segundo Pedrosa (2011), é importante frisar que as cisternas de placas implantadas pelo P1MC é uma tecnologia social que favorece: a mão de obra; promove a autogestão e controle sobre o modo de produção; não é hierarquizada; e tem como objetivo principal, não a maximização da produtividade, mas sim a resolução dos problemas sociais.

Em suma, as cisternas de placas do P1MC promovem inúmeros benefícios sociais e ambientais, pois: possibilita uma maior disponibilidade de água; otimiza o uso dos recursos hídricos; a captação de água precipitada sobre os telhados diminui a pressão sobre os reservatórios de água e mananciais; o aproveitamento de água de chuva promove a preocupação com o meio ambiente; a captação de água de chuva promove, de forma sustentável, o gerenciamento e uso da água; e possibilita mitigar os "efeitos adversos" atribuídos a escassez hídrica nos períodos de seca.

Por fim, a sustentabilidade de uma dada localidade pressupõe um conjunto de ações adotadas em conjunto com a sociedade civil, as quais possam desenvolver habilidades específicas que possibilitem o aproveitamento das potencialidades locais (CÂNDIDO et al., 2010). É nesta perspectiva que o P1MC tem possibilitado a execução de uma tecnologia social (cisternas de placas) concebida, executada e gerida pela sociedade civil organizada (ASA, inúmeras ONGs e instituições), tendo como objetivo maior a sustentabilidade no Semiárido brasileiro através do acesso e disponibilidade de água, o que tem proporcionado: a segurança alimentar e nutricional, e, principalmente, a promoção de uma nova cultura de uso e gestão dos recursos hídricos que tem possibilitado a convivência com o Semiárido.

\section{CONCLUSÕES}

A análise socioambiental da eficiência das cisternas de placas e do desempenho do "Programa Um Milhão de Cisternas Rurais - P1MC" no município de Pedra Lavrada permite concluir:

1) De acordo com a série de dados de precipitação (1952-2012), observou-se que com a precipitação correspondente e mediana da série foi de $366,3 \mathrm{~mm}$, e que esta é suficiente para preencher a capacidade máxima de captação de água de chuva (16 mil litros) de uma cisterna de 
placas do P1MC, o que evidencia as cisternas de placas como uma tecnologia eficiente para os cenários pluviométricos do Semiárido;

2) Tomando-se a mediana $(366,3 \mathrm{~mm})$ de precipitação da série para estimar o Volumes Potenciais de Captação (VPC), concluiu-se que: para uma área de $63 \mathrm{~m}^{2}$ (tamanho médio dos telhados das residências pesquisadas), tem-se um volume de 17,3 mil litros, o que é capaz de encher a cisterna (16 mil litros) e atender aos ditames do P1MC durante o período de estiagem (8 meses). Neste sentido, as cisternas de placas configuram-se numa tecnologia viável para a captação e gestão hídrica das águas precipitadas sobre os telhados das residências.

3) A eficiência das cisternas do P1MC enquanto tecnologia de gestão hídrica foi comprovada com a uma relação entre os VPC versus consumo, onde observou-se que: as cisternas de placas do P1MC (16 mil litros) suprem as necessidades hídricas básicas (água para beber e para higiene pessoal = 14 litros, por pessoa/dia) de uma família com até 4 pessoas;

4) Quanto à percepção social sobre o desempenho do P1MC, concluiu-se: i) no tocante à questão social, o P1MC permitiu melhores condições de vida: acesso e disponibilidade de água, e "independência hídrica"; e as cisternas de placas do P1MC é uma tecnologia social de fácil construção e de baixo custo, a qual tem melhorado as condições de vida das comunidades rurais através do acesso e disponibilidade de água;

5) Ao analisar os possíveis problemas correlacionados ao desempenho do P1MC, evidenciou-se a ausência de fiscalização para com os problemas das cisternas (rachaduras e vazamentos), e a falta de acompanhamento quanto aos necessidades familiares, já que a água das cisternas não atende a todos os anseios dos populares;

6) Quanto à utilização da água armazenada nas cisternas, observou que a água das cisternas tem múltiplos usos: consumo humano, higiene pessoal e doméstica e, em alguns casos, para a dessedentação de animais. Isto faz com que a água da cisterna atenda às demandas familiares por até 3,8 meses, tempo menor que o período de estiagem ( 8 meses). Com tal realidade as famílias são obrigadas a comprar água através de carro-pipa;

7) A construção das cisternas pelo P1MC tem promovido muitos benefícios socioambientais, a saber: maior disponibilidade de água; otimiza o uso dos recursos hídricos; a captação de água precipitada sobre os telhados diminui a pressão sobre os reservatórios de água e mananciais; a captação de água de chuva promove o gerenciamento e uso sustentável da água; e , principalmente, tem fomentado a "independência hídrica", o que contribui tanto para a sustentabilidade das famílias rurais, quanto para a convivência com as condições edafoclimáticas do Semiárido.

Por fim, torna-se imprescindível se ter em mente que não há um programa/tecnologia que seja a redenção do Semiárido brasileiro, pois qualquer que seja o programa/tecnologia, ele/ela não atenderá a todas as necessidades e/ou interesses, seja por limitações sociais, tecnológicas ou, principalmente, econômicas. Dessa forma, o P1MC tem contribuído, a seu modo, para a melhoria de vida de milhares de famílias através do fornecimento de uma tecnologia social de captação de água de chuva (cisternas de placas), a qual tem permitido melhores condições de sobrevivência e sustentabilidade em meio às adversidades do Semiárido brasileiro. 
Como sugestões, ressalva-se a importância de se buscar disseminar não só o uso das cisternas de placas, mas também de outras tecnologias/programas sociais $(P 1+2$, barragens subterrâneas, perfuração de poços artesianos, instalação de destiladores de água salobra, etc.), pois tais tecnologias/programas quando usadas em conjunto, podem corroborar para a convivência com o semiárido.

\section{AGRADECIMENTOS}

Gostaríamos de agradecer ao Programa de Pós-Graduação em Recursos Naturais da Universidade Federal de Campina Grande (UFCG) e a Coordenação de Aperfeiçoamento de Pessoal de Nível Superior (CAPES) pela bolsa de doutorado concedida ao primeiro e segundo autores, bem como somos extremamente gratos ao INMET, ASA, AESA pelas informações e dados fornecidos, e, especialmente, às famílias rurais do município de Pedra Lavrada-PB, que com confiança nos abriu as portas e partilharam conosco suas opiniões.

\section{REFERÊNCIAS BIBLIOGRÁFICAS}

1. ALMEIDA, H. A. \& SILVA, L. Estimativa para captação de água de chuva no Brejo Paraibano. In: Simpósio Brasileiro de Captação de Água de Chuva no Semiárido, Campina Grande - PB, 2001, CD-ROM, 2001.

2. ANDRADE-LIMA, D. The caatinga dominium. Revista Brasileira de Botânica, 4:149-153, 1981.

3. AESA- Agência Executiva de Gestão das Águas do Estado da Paraíba. Disponível em: http://www.aesa.pb.gov.br/. Acessado em: 01 de fevereiro de 2013.

4. ALVES, L. I. F.; SILVA, M. M. P.; VASCONCELOS, K. J. C. Visão de comunidades rurais em Juazeirinho/PB referente à extinção da biodiversidade da caatinga. Revista Caatinga. v. 21, n. 4, 2008.

5. ARTICULAÇÃO DO SEMIÁRIDO-ASA. Programa de Formação e Mobilização Social para a Convivência com o Semiárido: Um Milhão de Cisternas Rurais. Anexo II do Acordo de Cooperação Técnica e Financeira FEBRABAN e AP1MC, 2003.

6. ASSIS, F. N.; ARRUDA, H. V. PEREIRA, A. R.. Aplicações de Estatística à Climatologia: Teoria e prática. Pelotas, RS: UFPEL, 1996.

7. BARBETTA, P. A. Estatística aplicada às ciências sociais. 4. ed. Florianópolis: Ed. da UFSC, 2002.

8. BARBOSA, A. G (2005). Articulação no Semiárido brasileiro - ASA, ajudando a construir uma história de convivência a partir da captação e manejo da água de chuva. In: Simpósio Brasileiro de Captação e Manejo de Água de Chuva: Captação e Manejo de Água de Chuva para Sustentabilidade de Áreas Rurais e Urbanas - Tecnologias e Construção da Cidadania, Teresina - PI: ABCMAC, 2005, CD-ROM.

9. BRASIL. Governo Federal . Ministério do Meio Ambiente. Secretaria de Recursos Hídricos SRH. Plano Nacional de Recursos Hídricos. Brasília, 2005.

10. CÂNDIDO, G. A.; VASCONCELOS, A. C. F.; SOUZA, E. G. Índice de Desenvolvimento Sustentável para Municípios: Uma proposta de metodologia com a participação de atores sociais e institucionais. In: CÂNDIDO, G. A. (org.). Desenvolvimento sustentável e sistemas de 
indicadores de sustentabilidade: Formas de aplicações em contextos geográficos diversos e contingências especiais. 1 ed. Campina Grande: Editora Universitária da UFCG, 2010.

11. FOME ZERO - Sociedade Brasileira em Apoio ao Programa Fome Zero, 2005. Cisternas impulsionam transformações socioeconômicas no Semiárido brasileiro. Disponível em: <http://www.fomezero.org.br/publique/cgi/cgilua.exe/sys//start.htm?sid=2>. Acesso em: 19 maio 2012.

12. IBGE - Instituto Brasileiro de Geografia e Estatística. Cidades - 2010. Disponível em: <http://www.ibge.gov.br/cidadesat>. Acesso em: 29 fev. 2012.

13. MMA - Ministério de Meio Ambiente. Agência Nacional de Águas. Superintendência de Conservação de Água e Solo. Superintendência de Usos Múltiplos. Cadernos de Recursos Hídricos. Disponibilidades e Demandas dos Recursos Hídricos no Brasil, 2005.

14. OliVEIRA, G. C. S. NÓBREGA, R. S. ALMEIDA, H. A . Perfil socioambiental e estimativa do potencial para captação de água de chuva em Catolé de Casinhas, PE. Revista de Geografia, Universidade Federal do Pernambuco. v. 29, n. 1., 2012.

15. PEDROSA, A. de S. Avaliação da contribuição do Programa de Formação e Mobilização para a Convivência com o Semiárido: Um Milhão de Cisternas Rurais (P1MC) na Qualidade de Vida da População Rural do Município de Soledade - PB. In: Simpósio Brasileiro de Captação de Água de Chuva no Semiárido, Campina Grande - PB, 2011, CD-ROM.

16. SAMPAIO, Everaldo V. S. B. et. al. Desertificação no Brasil: conceitos, núcleos e tecnologias de recuperação e convivência. Recife, URPE, 2003.

17. SILVA, C. V. Qualidade da água de chuva para consumo humano armazenada em cisternas de placa: Estudo de caso, Araçuaí - MG. In: Simpósio Brasileiro de Captação e Manejo de Água de Chuva: Captação e Manejo de Água de Chuva, Belo Horizonte, 2006, CD-ROM.

18. SILVA, F. B. R.; et al. Zoneamento Agroecológico do Nordeste: Diagnóstico do quadro natural e agrossocioeconômico. Petrolina: EMBRAPA-CPATSA/Recife: EMBRAPACNPS/Coordenadoria Regional Nordeste, 1993.

19. THIOLLENT, M. (2005). Metodologia da pesquisa ação. 8. ed. São Paulo: Cortez, 2005. 